\title{
Immunotherapy for the management of cancer pain
}

\author{
Fumimasa Amaya^ \\ Department of Pain Management and Palliative Care Medicine, Kyoto Prefectural University of Medicine, Kyoto, Japan \\ Correspondence to: Fumimasa Amaya, MD, PhD. Department of Pain Management and Palliative Care Medicine, Kyoto Prefectural University of \\ Medicine, Kajii-cho 465, Kamigyo-Ku, Kyoto 6020841, Japan. Email: ama@koto.kpu-m.ac.jp. \\ Provenance and Peer Review: This article was commissioned by the editorial office, Annals of Palliative Medicine. The article did not undergo external \\ peer review. \\ Comment on: Zhou X, Qiao G, Ren J, et al. Adoptive immunotherapy with autologous T-cell infusions reduces opioid requirements in advanced \\ cancer patients. Pain 2020;161:127-34.
}

Submitted Apr 23, 2020. Accepted for publication May 19, 2020.

doi: 10.21037/apm-20-959

View this article at: http://dx.doi.org/10.21037/apm-20-959

Pain is a common symptom and one of the major burdens on cancer patients. The prevalence of pain is reportedly $40 \%$ for patients after curative treatment, $55 \%$ for patients during antitumor treatment and $>60 \%$ for patients with advanced metastatic cancer (1). Opioids have been the mainstay of current management for moderate to severe cancer pain. There has been no space to debate the utility of opioids for cancer pain treatment. However, concerns are growing about the long-term use of opioids due to unfavorable side effects including tolerance and dependence, sleep disordered breathing, endocrinopathy, cognitive dysfunction and immunosuppression (2). In addition, a not-insubstantial percentage of cancer patients reportedly experience opioid-refractory pain (3). A search for novel strategies to address pain is crucial to improving quality of life for cancer patients. Clinical and preclinical studies have classified cancer pain based on its etiology, such as inflammatory or neuropathic pain. However, etiology-based cancer treatment remains difficult in clinical settings (4).

Transfusion of adoptive immune cells activated ex vivo is an emerging option for antitumor treatment. Cytokineinduced killer (CIK) cells represent a heterogenous cell population of $\mathrm{T}$ lymphocytes generated from peripheral blood mononuclear cells co-cultured with several cytokines (5). These cells show potent, major histocompatibility complex (MHC)-independent tumorkilling activity and are suitable for adoptive cell transfer in antitumor immunotherapy. The tumor-killing activity is activated when dendritic cell (DC) are used in combination with CIK. Immunotherapy with CIK in combination with DCs (DC-CIK) has been shown to have effects on various solid and hematological tumors (6) without serious side effects (7).

Recently, transfusion of adoptive immune cells is reportedly associated with reductions in opioid consumption and pain intensity among patients with advanced cancer (8). Zhou et al. performed a retrospective chart review of cancer patients involved in the clinical study to test antitumor efficacy of autologous DC-CIK cell infusion. The authors analyzed opioid consumption of patients with cancer pain before and after immunotherapy with autologous DC-CIK cell infusion. Participants were individuals $>18$ years old who had been diagnosed with advanced, unresectable or metastatic solid tumors, adequate organ function, expected survival $>3$ months and Eastern cooperative oncology group physical status $>1$. Patients with previous transplants, active infections, autoimmune diseases or serious physical or psychiatric disorders were excluded. The overall number of participants was 357 . Of these, 55 patients were selected as they had received opioid treatment due to moderate to severe cancer pain. Daily pain intensity was measured using the numerical rating scale (NRS) and opioid consumption was recorded for two 2-week periods, before and after DCCIK treatment.

Worst NRS score and daily opioid consumption

^ORCID: 0000-0003-2934-0845. 
decreased significantly after DC-CIK treatment. Twentythree of the 55 patients were identified as responders, defined as participants in whom opioid consumption decreased $>20 \%$. Importantly, this effect showed no association with tumor regression, based on the results of diagnostic imaging with computed tomography and/or magnetic resonance imaging. Multivariate analysis identified a greater number of DC-CIK cells transfused as associated with better pain relief.

Several mechanisms are supposed to be involved in antinociceptive effect of autologous cell infusion observed in Zhou's study. The authors suggested increased production of endogenous opioids due to activation $\mathrm{CD}^{+} \mathrm{T}$ lymphocytes. In this study, infusion of $\mathrm{CD}^{+} / \mathrm{CD}^{+}$positive cells showed a greater association with pain relief than infusion of $\mathrm{CD}^{+} / \mathrm{CD}^{+}$cells. Animal experiments showed that infusion of activated $\mathrm{CD} 4^{+} \mathrm{T}$ lymphocytes reduced hypersensitivity to visceral and somatic pain $(9,10)$. CD4 ${ }^{+}$ $\mathrm{T}$ lymphocytes are capable of releasing endogenous opioids and their analgesic efficacy is thus dependent on the opioid system (11). A recent animal study suggested that infusion of chemokine C-C motif ligand 4 (CCL-4) (12) or Chinese herb cinobufagin (13) evokes anti-nociception through the activation of $\mathrm{CD}^{+} \mathrm{T}$ lymphocytes and the peripheral opioid system. Pharmacological manipulation of endogenous $\mathrm{CD}^{+} \mathrm{T}$ lymphocytes might offer an attractive strategy for achieving pain relief.

In addition to its systemic efficacy, DC-CIK infusion might have local influences on tumor tissue. Sensory nerve endings are a central component of the tumor microenvironment. Chemical crosstalk exists between tumor cells and sensory nerve endings (14). Tumor cells release arachidonic acid, neurotrophic factors and neurotransmitters that lead to the sensitization of sensory nerves (15). Conversely, several biological substances released from sensory nerve endings can support tumor growth in vivo and in vitro $(16,17)$. While Zhou et al. accumulated no clear evidence regarding tumor remission, DC-CIK treatment may affect the signaling between tumor cells and sensory nerves, leading to anti-nociception.

In addition, mounting evidence suggests significant roles of immune cells in the sensory nervous system for pain pathophysiology, including cancer pain (18). Monocytes, macrophages and $\mathrm{T}$ lymphocytes in the peripheral nervous system and spinal cord play crucial roles in pain regulation. For instance, infusion of anti-inflammatory regulatory $\mathrm{T}$ lymphocytes alleviated chemotherapy-induced neuropathic pain (19). Immunotherapy with DC-CIK might have influenced immune cell activity in the sensory nervous system to alleviate pain.

The observations of Zhou et al. appear highly relevant, but several important limitations to the study must be noted. As the authors described, this study was performed using a retrospective design. Pain in cancer patients did not seem to be the main outcome of the initial trial, and thus was not well characterized. Participants were chosen from the original cohort after completion of the study. Diagnostic imaging to determine tumor remission was only performed for 34 of 55 patients. In addition, pain intensity and opioid consumption were observed for only 2 weeks after infusion. This study thus did not see longer analgesic efficacy. Obviously, the results of prospective analyses are needed before any conclusions can be reached regarding the antinociceptive effects of autologous DC-CIK infusion therapy in cancer patients.

A similar strategy using mesenchymal stem cells (MSCs) has been tested to relieve pain due to bone cancer pain or osteoarthritis. Injection of autologous MSCs into the joint alleviated pain in patients with osteoarthritis (20). Intrathecal injection of bioengineered MSCs has been shown to exert antinociceptive effects in animal models of bone cancer pain (21). Cell-based pain therapy might represent a promising option to treat chronic pain.

\section{Acknowledgments}

Funding: None.

\section{Footnote}

Conflicts of Interest: The author has completed the ICMJE uniform disclosure form (available at http://dx.doi. org/10.21037/apm-20-959). FA reports grants and personal fees from SHIONOGI \& CO., LTD.; Daiichi Sankyo Company, Limited; Maruishi Pharmaceutical Co.Ltd; grants from Nippon Zoki Pharmaceutical Co., outside the submitted work.

Ethical Statement: The author is accountable for all aspects of the work in ensuring that questions related to the accuracy or integrity of any part of the work are appropriately investigated and resolved.

Open Access Statement: This is an Open Access article distributed in accordance with the Creative Commons Attribution-NonCommercial-NoDerivs 4.0 International 
License (CC BY-NC-ND 4.0), which permits the noncommercial replication and distribution of the article with the strict proviso that no changes or edits are made and the original work is properly cited (including links to both the formal publication through the relevant DOI and the license). See: https://creativecommons.org/licenses/by-nc-nd/4.0/.

\section{References}

1. van den Beuken-van Everdingen MH, Hochstenbach LM, Joosten EA, et al. Update on Prevalence of Pain in Patients With Cancer: Systematic Review and Meta-Analysis. J Pain Symptom Manage 2016;51:1070-1090.e9.

2. Davis MP, Mehta Z. Opioids and Chronic Pain: Where Is the Balance? Curr Oncol Rep 2016;18:71.

3. Meuser T, Pietruck C, Radbruch L, et al. Symptoms during cancer pain treatment following $\mathrm{WHO}$-guidelines: a longitudinal follow-up study of symptom prevalence, severity and etiology. Pain 2001;93:247-57.

4. Bennett MI. Mechanism-based cancer-pain therapy. Pain 2017;158 Suppl 1:S74-8.

5. Guo Y, Han W. Cytokine-induced killer (CIK) cells: from basic research to clinical translation. Chin J Cancer 2015;34:99-107.

6. Garofano F, Gonzalez-Carmona MA, Skowasch D, et al. Clinical Trials with Combination of Cytokine-Induced Killer Cells and Dendritic Cells for Cancer Therapy. Int J Mol Sci 2019;20:4307.

7. Schmeel LC, Schmeel FC, Coch C, et al. Cytokineinduced killer (CIK) cells in cancer immunotherapy: report of the international registry on CIK cells (IRCC). J Cancer Res Clin Oncol 2015;141:839-49.

8. Zhou X, Qiao G, Ren J, et al. Adoptive immunotherapy with autologous T-cell infusions reduces opioid requirements in advanced cancer patients. Pain 2020;161:127-34.

9. Verma-Gandhu M, Bercik P, Motomura Y, et al. CD4+ T-cell modulation of visceral nociception in mice. Gastroenterology 2006;130:1721-8.

Cite this article as: Amaya F. Immunotherapy for the management of cancer pain. Ann Palliat Med 2020;9(4):13581360. doi: 10.21037/apm-20-959
10. Boué J, Blanpied C, Brousset P, et al. Endogenous opioidmediated analgesia is dependent on adaptive $\mathrm{T}$ cell response in mice. J Immunol 2011;186:5078-84.

11. Basso L, Boue J, Mahiddine K, et al. Endogenous analgesia mediated by CD4(+) T lymphocytes is dependent on enkephalins in mice. J Neuroinflammation 2016;13:132.

12. García-Domínguez M, Lastra A, Folgueras AR, et al. The Chemokine CCL4 (MIP-1 $\beta$ ) Evokes Antinociceptive Effects in Mice: a Role for CD4+ Lymphocytes and MetEnkephalin. Mol Neurobiol 2019;56:1578-95.

13. Chen T, Yuan S, Wan XN, et al. Chinese herb cinobufaginreduced cancer pain is associated with increased peripheral opioids by invaded CD3/4/8 lymphocytes. Oncotarget 2017;8:11425-41.

14. Saloman JL, Albers KM, Rhim AD, et al. Can Stopping Nerves, Stop Cancer? Trends Neurosci 2016;39:880-9.

15. Mantyh P. Bone cancer pain: causes, consequences, and therapeutic opportunities. Pain 2013;154 Suppl 1:S54-62.

16. Saloman JL, Albers KM, Li D, et al. Ablation of sensory neurons in a genetic model of pancreatic ductal adenocarcinoma slows initiation and progression of cancer. Proc Natl Acad Sci U S A 2016;113:3078-83.

17. Keskinov AA, Tapias V, Watkins SC, et al. Impact of the Sensory Neurons on Melanoma Growth In Vivo. PLoS One 2016;11:e0156095.

18. Ji RR, Chamessian A, Zhang YQ. Pain regulation by nonneuronal cells and inflammation. Science 2016;354:572-7.

19. Liu XJ, Zhang Y, Liu T, et al. Nociceptive neurons regulate innate and adaptive immunity and neuropathic pain through MyD88 adapter. Cell Res 2014;24:1374-7.

20. Harrell CR, Markovic BS, Fellabaum C, et al. Mesenchymal stem cell-based therapy of osteoarthritis: Current knowledge and future perspectives. Biomed Pharmacother 2019;109:2318-26.

21. Sun Y, Tian Y, Li H, et al. Antinociceptive Effect of Intrathecal Injection of Genetically Engineered Human Bone Marrow Stem Cells Expressing the Human Proenkephalin Gene in a Rat Model of Bone Cancer Pain. Pain Res Manag 2017;2017:7346103. 